American Journal of Mechanical and Industrial Engineering
2020; 5(5): $64-70$
http://www.sciencepublishinggroup.com/j/ajmie
doi: 10.11648 /j.ajmie.20200505.11
ISSN: 2575 -6079 (Print); ISSN: $2575-6060$ (Online)

\title{
Optimization of Investment Casting Parameters to Improve the Mechanical Properties by Taguchi Method
}

\author{
Nil Ratan Mondal ${ }^{1, ~ *, ~ M d . ~ R a f i q u z z a m a n ~}{ }^{1}$, Md. Abubakar Siddique ${ }^{2}$, Sibbir Islam $^{3}$ \\ ${ }^{1}$ Department of Industrial Engineering and Management, Khulna University of Engineering \& Technology (KUET), Khulna, Bangladesh \\ ${ }^{2}$ Department of Industrial and Production Engineering, Bangladesh Army University of Science and Technology, Saidpur, Bangladesh \\ ${ }^{3}$ GSM Composite Knitting Industries Ltd., Gazipur, Dhaka
}

\section{Email address:}

nilratan33@gmail.com (N. R. Mondal), rafiqbitr@yahoo.com (Md. Rafiquzzaman), sibbirislam@gmail.com (S. Islam)

${ }^{*}$ Corresponding author

\section{To cite this article:}

Nil Ratan Mondal, Md. Rafiquzzaman, Md. Abubakar Siddique, Sibbir Islam. Optimization of Investment Casting Parameters to Improve the Mechanical Properties by Taguchi Method. American Journal of Mechanical and Industrial Engineering. Vol. 5, No. 5, 2020, pp. 64-70. doi: 10.11648/j.ajmie.20200505.11

Received: November 27, 2019; Accepted: February 3, 2020; Published: October 12, 2020

\begin{abstract}
Investment casting is the most adaptable and durable manufacturing process dating back thousands of years, with a rapidly increasing application. It is used primarily for the development of complex components near net-shape. A wax pattern in the exact replica of the cast part is used here. When the mold has been formed, the wax pattern is melted out. For this purpose this process is called lost wax process. In this present study investment casting process parameter is optimized by using Taguchi approach to improve the mechanical properties of mild steel. A set of experiments were conducted as per Taguchi's L9 orthogonal array to determine the most influential control factors. For test the performance characteristics, orthogonal range, signal to noise ratio and variance analysis were used. Data values are obtained under the constraint of different process parameters like preheat temperature, pouring temperature, preheat time to investigate their effects on the surface hardness, tensile strength of the final results. The variations in the trend of the mechanical properties were observed. It was found that high mold preheat temperature, higher pouring temperature, maximum preheat time significantly reduce the mechanical properties of the castings.
\end{abstract}

Keywords: Investment Casting, Taguchi Method, S/N Ratio, Orthogonal Array, Optimization, Casting Parameter, Taguchi Technique, ANOVA Analysis

\section{Introduction}

Investment casting (also known as 'lost wax casting' or 'precision casting') has been a widely used process for hundreds of years [1]. It is one of the primeval casting processes, in which into an expendable ceramic mold molten metal is poured. It is also considered to be the most ancient process of making art castings. Technological advances have also made it to be the most modern and versatile one among all the metal casting processes [2].

In the shape of the desired part, by using a wax pattern the mold is formed. The wax pattern is dipped into ceramic slurry which hardens into the ceramic mold [3]. When the mold has been formed the wax pattern is melted out. For this reason investment is known as "lost wax casting". It is widely used for making parts having sophisticated shapes and rigid tolerances [4]. The components and machines which are used in investment casting are wax pattern, ceramic slurry, metal die, ferrous or non-ferrous metal, cutting and sand blasting machine. There is no question that casting as a manufacturing process requires so many parameters such as melting temperature of the charge, mold temperature, pouring velocity and temperature. composition, microstructure, casting volume, runner size, alloy composition and solidification time. The quality of casting are influenced by casting parameters [5]. Some researchers have successfully carried out studies on the varying effects of investment casting process parameters on the mechanical properties of casted metals and their alloys [5-9].

Jones et al. [6] concluded that if the refractory coating 
slurry is not permitted to drain evenly, the pattern may have an irregular thickness which may affect its strength. Jones and Yuan [7] found that a weakened ceramic shell structure can lower the quality of an investment casting. The strength of a ceramic shell mold depends upon mold material, shell making procedure, and firing temperature.

Yuan et al. [8] presented a paper which explains the fiber modified ceramic shell and polymer modified system. Polymer modified system has more green strength than fiber modified ceramic shell. Although the modified polymer system has a higher resistance in the green dry stage, molds produced with fiber additions are less susceptible to autoclave cracking in practice.

$\mathrm{Li}$ et al. [9] presented a paper which explain that mechanical properties and micro porosity of the cast items are influenced by ceramic preheat temperature, pouring temperature, melt hydrogen content. They concluded that the amount of micro porosity in the investment casting process is determined by hydrogen content and shell preheat temperature. By increasing with the hydrogen content and shell preheat temperature, the porosity is also increased. High mechanical properties are generally created by low pouring temperature.

Baumeisth et al. [10] presented a paper which describes the effect of casting parameters on microstructures and the mechanical properties of extremely small micro-casting pieces. He concluded that by increasing with the mold temperature, the edges of the specimen also become sharper. High mold temperature also results in the transfer of extremely fine details such as cracks and other surface defects from the mold on to the cast part. One of the recent Japanese scholar Engr. Dr. Genichi Taguchi in 1950.

Taguchi method is a statistical approach to improve the quality of the manufactured components. It provides effective and standardized way to optimize design for performance and price [12]. This approach is appropriate when design parameters are subjective. Most important optimization processes is the Taguchi method [11] conceived and developed by Taguchi parameter design can improve performance characteristics by setting design parameters and scale down system performance sensitivity to origin of variability [13-14].

Hence, with this background, it is concluded that the investment casting quality is greatly affected by its various process parameters. Therefore, in this present study, an attempt has been made to determine the optimal settings of investment casting process parameters such as pouring temp, preheat temp and preheat time for achieving optimum mechanical properties using Taguchi's experimental design method. Taguchi method is a streamlined type of experimental design (DOE), where the experiments are systematically planned and evaluated to enhance the performance characteristics. ANOVA was used for analyzing the results of designed experiments. Finally, it was found that Taguchi optimization processes help to obtain the optimal settings process parameters of investment casting process for achieving improved mechanical properties.

\section{Methodology}

\section{Selection of Materials}

In this present investigation mild steel has been taken to make the castings. It is a steel alloy, with a minimum of $11.5 \%$ chromium content by mass and a maximum of 0.05 $0.30 \%$ carbon by mass. Stainless steels are most notable for their resistance to corrosion, which increases as chromium content increases.

Table 1. The Chemical Composition of Stainless Steel.

\begin{tabular}{llllllll}
\hline Amount & $\mathbf{C} \%$ & Si \% & Mn \% & S \% & P \% & Cr \% & Ni \% \\
\hline Min & 0.10 & 0.15 & 0.40 & - & - & - & - \\
$\operatorname{Max}$ & 0.18 & 0.35 & 0.70 & 0.04 & 0.04 & - & - \\
\hline
\end{tabular}

Selection of Process Parameters

In this study three process parameter is considered such as Preheat temperature, pre heat time and pouring temperature.

Preheat Temperature

Usually, the mold is preheated before pouring the liquid metal into investment casting to minimize the thermal shock due to rapid cooling. Just before the pour, the mould is preheated to a temperature in the range of $1000-1200^{\circ} \mathrm{C}$ to remove any residues of wax and harden the binder. According to the different properties of differ alloys this range of preheat temperature varies in this section for stainless steel investment casting it varies in the range 1000$1200^{\circ} \mathrm{C}$. The pour in the pre-heated mould also ensures that the mould will fill completely. Increasing preheat reduces the amount of heat a mold can absorb, the thermal gradient across the mold, and the amount by which it will expand when heated.

Preheat Time

The duration of preheating or burn out the mould to remove any residues of wax and harden the binder, before pouring the molten metal. A two stage burnout methods was selected. This burnout schedule was for 30 minutes from room temperature to $250^{\circ} \mathrm{C}$ and then the temperature was increased to $900^{\circ} \mathrm{C}$. Once the maximum temperature was reached, the mould was heat soaked for half an hour. Maintain the desired temperature for at least 2 hours. Heat for longer periods of time for large patterns, and occasionally burn a second time for extremely large patterns.

Pouring Temperature

In investment casting the temperature while pouring the molten metal into the mould. The temperature of metal pouring varies significantly depending on the particular alloy used. The ceramic molds in investment casting can be brought to more than $1,500 \mathrm{~F}(816 \mathrm{C})$, thus increasing their strength. This allows for high-temperature pours. The pouring temperature for most aluminum alloys typically $750^{\circ} \mathrm{C}$. These temperatures ensure the most effective pouring procedures and enable smoother methods of cooling when casting into the ceramic shell. These temperatures ensure the most effective pouring procedures and enable smoother methods of cooling when casting into the ceramic shell. The amount of shrinkage and the solidification time also increase with pouring temperature. 
The above system variables have been chosen to demonstrate their effect on dimensional accuracy and mechanical properties of cast components developed by investment

casting process. Process variables and their range with levels were selected for the study are shown in the table.

These ranges that were divided into the three levels according to the Taguchi method are as shown in the Table 2.

Table 2. Process Variables and Their Range with Levels.

\begin{tabular}{lllll}
\hline \multirow{2}{*}{ Factors } & \multirow{2}{*}{ Range } & \multicolumn{3}{c}{ Levels } \\
\cline { 3 - 5 } & & L1 & L2 & L3 \\
\hline Preheat temperature (A) & $900^{\circ} \mathrm{C}-1000^{\circ} \mathrm{C}$ & 900 & 950 & 1000 \\
Preheat time (B) & $2-3 \mathrm{Hrs}$ & 2 & 2.5 & 3 \\
Pouring temperature (C) & $1500-1600$ & 1500 & 1550 & 1600 \\
\hline
\end{tabular}

\section{Casting Procedure}

First 9 wax patterns in the shape of test bar were made. Then the wax pattern were assembled onto the sprue. Then successive layers of ceramic and stucco were applied to form a hard shell onto the sprue assembly. To form a hard shell the sprue assembly were dipped into ceramic slurry (primary slurry) and drained to get an even wet coating. Then, primary stucco consisting of coarse ceramic grit was applied over the wet coating and dried. The grit adheres to the wet ceramic coating. Then, in the similar way, secondary layer was built up over the primary layer. But with a difference that the secondary layer was made from coarser flour and coarser stucco as compared to primary layer.

Gradually, secondary stucco size is increased to enhance the porosity of the ceramic shell. Finally, a seal coat is given to the shell. Total five layers are given to all shells so as to obtain near about uniform shell thickness. After drying, the shells were dewaxed. Then 9 castings were done with the variation of process variables. On the first casting the shell was heated up to $900^{\circ} \mathrm{C}$ about 2 hours. After that molten metal heated up to $1500^{\circ} \mathrm{C}$ was poured into the shell and keep the shell in the air for cooling. Same way other 8 castings were done with the variation of process variables given in the table 2 .

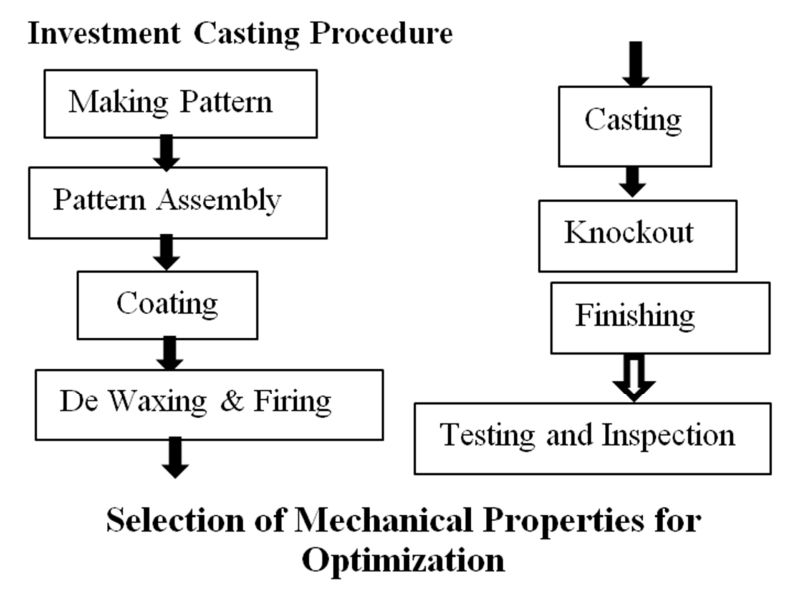

Figure 1. Flow Diagram of Casting Process.

After casting have been done the following mechanical properties was selected for optimization.

Tensile Strength

Ultimate tensile strength (UTS), often shortened to tensile strength (TS) or ultimate strength is the material or structure's ability to withstand loads that tend to elongate, as opposed to compressive strength which absorbs loads that tend to decrease in volume. The tensile strength was measured as Indian standard in universal testing machine (UTM).

Hardness

Hardness is a measure of how strong solid matter changes when a compressive force is applied to different types of permanent material. Many materials (such as metals) are more complicated than others (such as plastics). Clear intermolecular bonds typically characterize macroscopic hardness, but the behavior of solid materials under pressure is complex. Thus specific hardness measures exist: scratch hardness, hardness of indentation, and hardness of rebound. Here hardness was teasted as per Brinell hardness test procedure.

\section{Optimization}

Taguchi Methods

Dr. Taguchi has developed a method focused on experiments with "ORTHOGONAL ARRAY," which provides much reduced "variance" for experiments with "optimal settings" of control parameters.

This statistical method is used to improve the quality of manufactured goods and more recently also applied to engineering, biotechnology, marketing and advertising. "Orthogonal Arrays" (OA) provide a set of experiments that are well balanced (minimum) and Dr. Taguchi's Signal-toNoise ratios $(\mathrm{S} / \mathrm{N})$, which are log functions of desired output, support in data analysis and prediction of optimum results as objective functions for optimizaton.

Table 3. Experimental layout Based on L9 Orthogonal Array.

\begin{tabular}{llll}
\hline Trial Number & A & B & C \\
\hline 1 & 1 & 1 & 1 \\
2 & 1 & 2 & 2 \\
3 & 1 & 3 & 3 \\
4 & 2 & 1 & 2 \\
5 & 2 & 2 & 3 \\
6 & 2 & 3 & 1 \\
7 & 3 & 1 & 3 \\
8 & 3 & 2 & 1 \\
9 & 3 & 3 & 2 \\
\hline
\end{tabular}

\section{Results and Discussion}

Table 3 shows experimental results of investment casting according to process parameters of Taguchi L9 orthogonal array for Brinell hardness number and Ultimate Tensile Strength.

Experiment no. 2 provides the maximum Brinell hardness number (149), where preheat time, preheat temperature, and pouring temperature are $2 \mathrm{hrs}, 950^{\circ} \mathrm{C}$ and $1550^{\circ} \mathrm{C}$ respectively. On the other hand, experiment no. 6 gives the maximum ultimate tensile strength $(460 \mathrm{MPa})$, where preheat 
time, preheat temperature, and pouring temperature are $2.5 \mathrm{hrs}, 1000^{\circ} \mathrm{C}$ and $1500^{\circ} \mathrm{C}$ respectively.

Table 4. Experimental results of investment casting for taguchi $L 9$ orthogonal array.

\begin{tabular}{llllll}
\hline Expt. No. & Pre heat Time (hrs) & $\begin{array}{l}\text { Preheat Temperature } \\
\left({ }^{\mathbf{C}}\right)\end{array}$ & $\begin{array}{l}\text { Pouring Temperature } \\
\left({ }^{\mathbf{C}}\right)\end{array}$ & $\begin{array}{l}\text { Brinell Hardness } \\
\text { Number (BHN) }\end{array}$ & $\begin{array}{l}\text { Ultimate Tensile } \\
\text { Strength (MPa) }\end{array}$ \\
\hline 1 & 2 & 900 & 1500 & 143 & 455 \\
2 & 2 & 950 & 1550 & 149 & 430 \\
3 & 2 & 1000 & 1600 & 143 & 452 \\
4 & 2.5 & 900 & 1550 & 147 & 425 \\
5 & 2.5 & 950 & 1600 & 144 & 455 \\
6 & 2.5 & 1000 & 1500 & 148 & 460 \\
7 & 3 & 900 & 1600 & 145 & 447 \\
8 & 3 & 950 & 1500 & 146 & 457 \\
9 & 3 & 1000 & 1550 & 148 & 435 \\
\hline
\end{tabular}

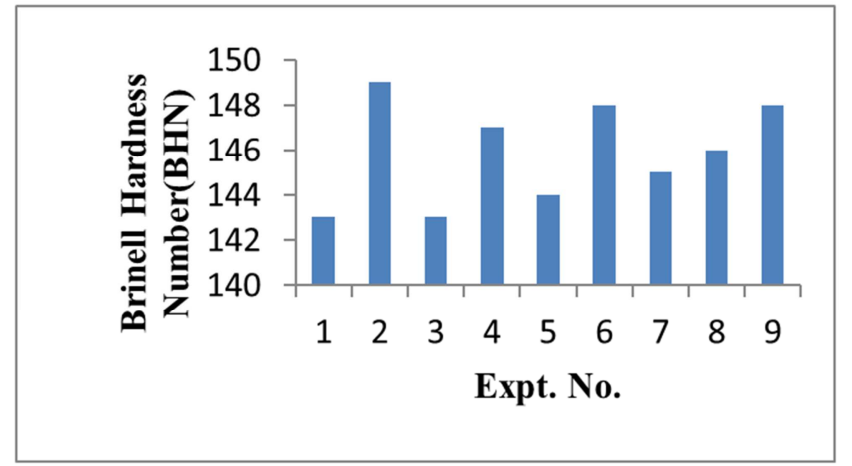

Figure 2. Comparison of Brinell hardness number of Different Experiment.

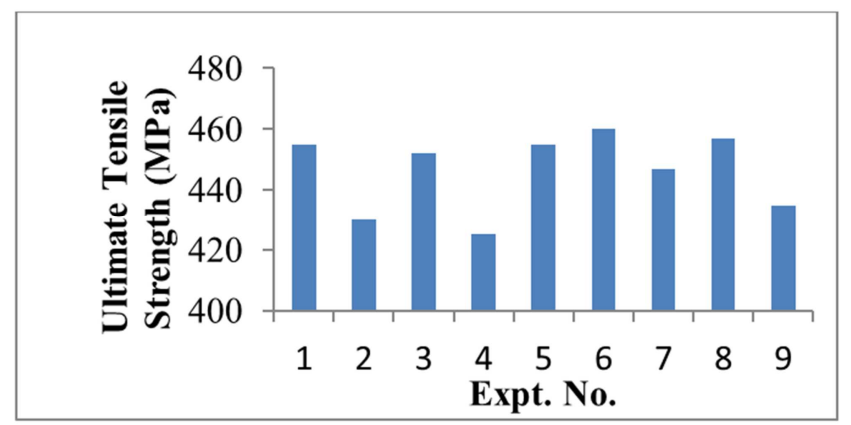

Figure 3. Comparison of Ultimate Tensile strength of Different Experiment.

\subsection{Taguchi Analysis}

\subsubsection{Brinell Hardness Number}

From table 5 and figure 4 , it is said that pouring temperature is the most influential factor as the most variation of Brinell hardness number for investment casting is from this factor, and also delta or response range is maximum for this factor that is seen in table 5 and so it is ranked as 1 . But it is specific point sensitive, level value of $1550^{\circ} \mathrm{C}$ results in maximum response value. Increasing the temperature may cause less BHN. Also BHN is below average for both level values of $1500^{\circ} \mathrm{C}$ and $1600^{\circ} \mathrm{C}$. For level value of $1600^{\circ} \mathrm{C}$, response is very much concerning as it is the lowest point that is not expected. This level value should be avoided while selecting value for pouring temperature. Responses for preheat time and preheat temperature seem alike. Very poor response in case of $2.0 \mathrm{hrs}$ preheat time, $2.5 \mathrm{hrs}$ presents better result than previous, but $3 \mathrm{hrs}$ is not satisfactory, it may be for some random errors in this process. Preheat temperature of $950^{\circ} \mathrm{C}$ is economical. No further improvement after increasing it to $1000^{\circ} \mathrm{C}$.

Table 5. Response Table for Means of Brinell Hardness Number.

\begin{tabular}{llll}
\hline Level & Preheat Time (hrs) & $\begin{array}{l}\text { Preheat } \\
\text { Temperature }\left({ }^{\circ} \mathbf{C}\right)\end{array}$ & $\begin{array}{l}\text { Pouring } \\
\text { Temperature }\left({ }^{\circ} \mathbf{C}\right)\end{array}$ \\
\hline 1 & 145.0 & 145.0 & 145.7 \\
2 & 146.3 & 146.3 & 148.0 \\
3 & 146.3 & 146.3 & 144.0 \\
Delta & 1.3 & 1.3 & 4.0 \\
Rank & 2.5 & 2.5 & 1 \\
\hline
\end{tabular}

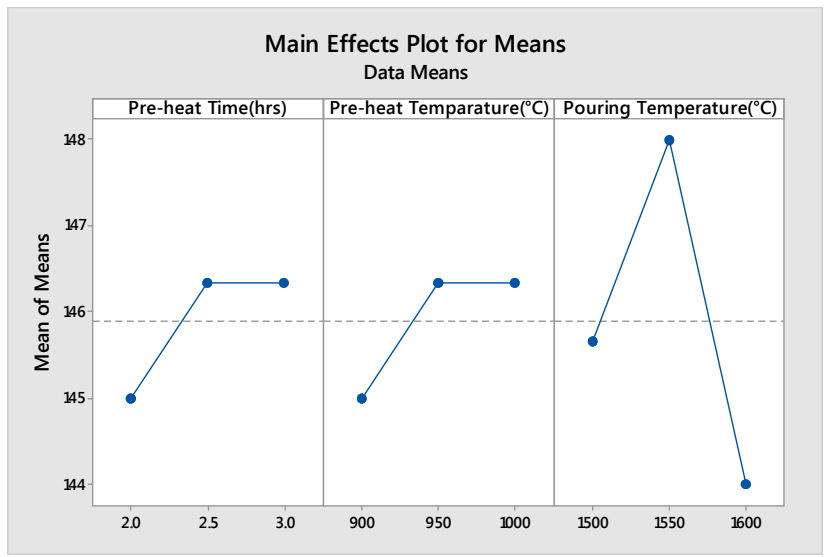

Figure 4. Main Effect Plots for Mean Values of Brinell hardness number.

\subsubsection{Ultimate Tensile Strength}

Table 6. Response Table for Means of Ultimate Tensile Strength.

\begin{tabular}{llll}
\hline Level & $\begin{array}{l}\text { Preheat } \\
\text { Time }(\mathbf{h r s})\end{array}$ & $\begin{array}{l}\text { Preheat } \\
\text { Temperature }\left({ }^{\circ} \mathbf{C}\right)\end{array}$ & $\begin{array}{l}\text { Pouring } \\
\text { Temperature }\left({ }^{\circ} \mathbf{C}\right)\end{array}$ \\
\hline 1 & 445.7 & 442.3 & 457.3 \\
2 & 446.7 & 447.3 & 430.0 \\
3 & 446.3 & 449.0 & 451.3 \\
Delta & 1.0 & 6.7 & 27.3 \\
Rank & 3 & 2 & 1 \\
\hline
\end{tabular}

From table 6 and figure 5 it is seen that preheat time has very little impact on ultimate tensile strength for investment 
casting. Preheat time of 2 hrs provides strength below mean value, level value of $2,5 \mathrm{hrs}$ shows a little bit better response than other twos. Preheat temperature has linearly increasing relation for improving ultimate tensile strength. Level value of $1000^{\circ} \mathrm{C}$ provides improve result and it may be possible make further improvement by increasing level value to a certain point. Pouring temperature is very sensitive to specific point value. The worst result is obtained from level value of $1550^{\circ} \mathrm{C}$, but much better or it can be said the best result from level value of $1500^{\circ} \mathrm{C}$. After increasing to $1600^{\circ} \mathrm{C}$, it again starts to improve strength from previous point. So there is a scope to check its possibility to get better response by increasing value after $1600^{\circ} \mathrm{C}$ pouring temperature.

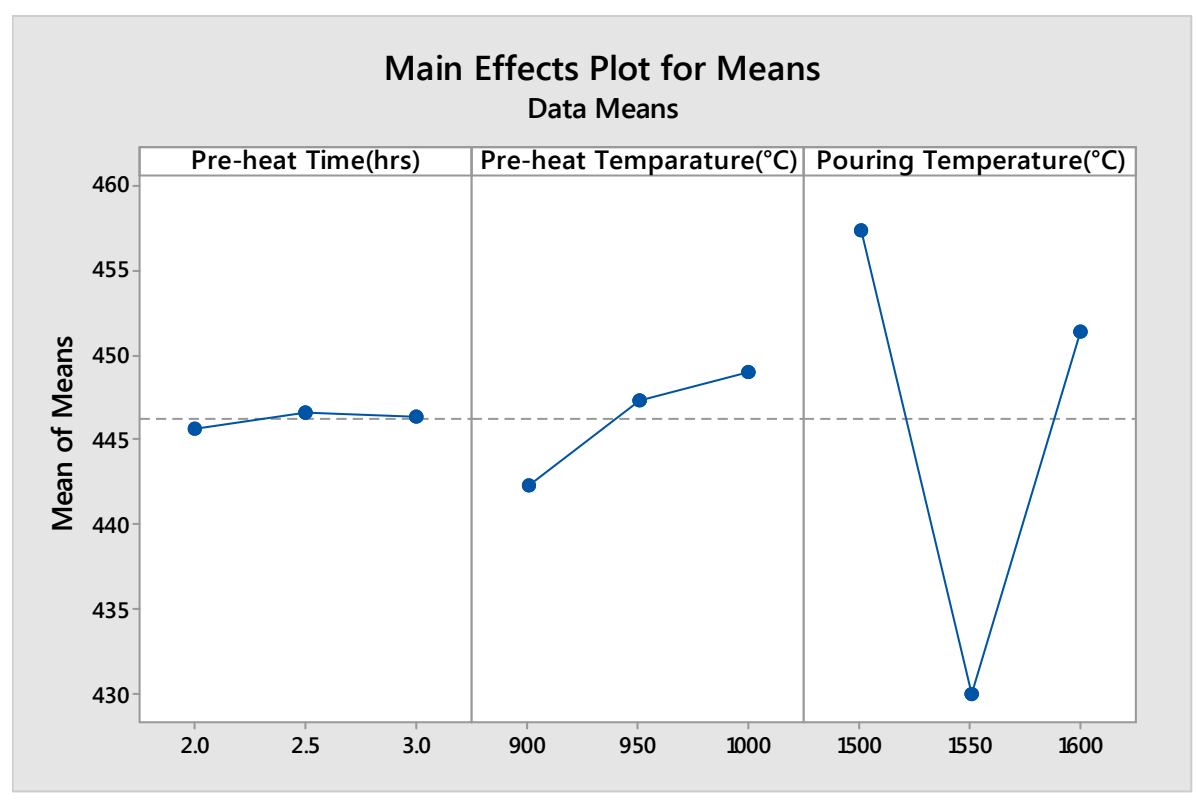

Figure 5. Main Effect Plots for Mean Values of Ultimate Tensile Strength.

\subsection{Analysis of Variance (ANOVA)}

\subsubsection{Brinell Hardness Number}

Table 7. ANOVA for Brinell hardness number at 95\% Confidence Level.

\begin{tabular}{llllll}
\hline Source & DF & Adj SS & Adj MS & F Value & P Value \\
\hline Preheat Time $(\mathrm{hrs})$ & 2 & 3.566 & 1.778 & 0.37 & 0.729 \\
Preheat Temperature $\left({ }^{\circ} \mathrm{C}\right)$ & 2 & 3.566 & 1.778 & 0.37 & 0.729 \\
Pouring Temperature $\left({ }^{\circ} \mathrm{C}\right)$ & 2 & 24.222 & 12.111 & 2.53 & 0.283 \\
Error & 2 & 9.556 & 4.778 & & $5.72 \%$ \\
Total & 8 & 40.889 & & & \\
\hline
\end{tabular}

From this ANOVA table (table 7), the maximum percentage of contribution was found $59.21 \%$ for pouring temperature. From F-distribution table, for numerator 2 and denominator 2, critical value Fcritical=19.00. In this study, calculated F-value is 2.53 which is smaller than critical Fvalue. So, P-value is 0.283 or $28.3 \%$ which is higher than $5 \%$ that indicates the high probability of accepting the decision on high contribution for the factor of pouring temperature.
Similarly, the minimum percentage of contribution was found $8.72 \%$ both for preheat time and preheat temperature. Here, calculated F-value is 0.37 which is smaller than 19.00 . So, Pvalue is 0.729 or $72.9 \%$ which is greater than $5 \%$ that also indicates the high probability of acceptance. In this analysis, combinational effects of factors that are not considered, contribute $23.36 \%$ as error.

\subsubsection{Ultimate Tensile Strength}

Table 8. ANOVA for Ultimate Tensile Strength at 95\% Confidence Level.

\begin{tabular}{|c|c|c|c|c|c|c|}
\hline Source & DF & Adj SS & Adj MS & F-Value & P-Value & Percentage Contribution \\
\hline Preheat Time (hrs) & 2 & 1.56 & 0.778 & 0.07 & 0.933 & $0.12 \%$ \\
\hline Preheat Temperature $\left({ }^{\circ} \mathrm{C}\right)$ & 2 & 72.22 & 36.111 & 3.35 & 0.230 & $5.42 \%$ \\
\hline Pouring Temperature $\left({ }^{\circ} \mathrm{C}\right)$ & 2 & 1238.22 & 619.111 & 57.44 & 0.017 & $92.85 \%$ \\
\hline Total & 8 & 1333.56 & & & & \\
\hline
\end{tabular}


From this ANOVA table (table 8), the maximum percentage of contribution was found $92.85 \%$ for pouring temperature. From F-distribution table, for numerator 2 and denominator 2, critical value Fcritical $=19.00$. In this study, calculated F-value is 57.44 which is larger than critical Fvalue. So, $\mathrm{P}$-value is 0.017 or $1.7 \%$ which is smaller than $5 \%$ that indicates the high probability of rejecting the decision on high contribution for the factor of pouring temperature. Similarly, the minimum percentage of contribution was found $0.12 \%$ for preheat time. Here, calculated F-value is 0.07 which is smaller than 19.00 . So, P-value is 0.933 or $93.3 \%$ which is greater than $5 \%$ that also indicates the high probability of acceptance. In this analysis, combinational effects of factors that are not considered, contribute $1.62 \%$ as error.

\subsection{Regression Analysis}

The regression analysis is a numerical means for the examination of interaction between various parameters of process. In this study, the optimal mechanical properties for investment casting are obtained by means of regression analysis using MINITAB 17. The feature of the regression equation is formed by providing input and output parameters in the Taguchi L9 orthogonal array in DOE. This helps to determine the cause result of one variable upon another. The equations are formed based on the value of three factors in case of investment casting.

\subsubsection{Brinell Hardness Number}

The regression equation of Brinell hardness number for the investment casting is as follows:

Brinell Hardness Number $(\mathrm{BHN})=155.7-0.0167$ Pouring Temperature $\left({ }^{\circ} \mathrm{C}\right)+1.33$ Preheat Time $(\mathrm{hrs})+0.0133$ Preheat Temperature $\left({ }^{\circ} \mathrm{C}\right)$.

Figure 6 shows the comparison between experimental and predicted Brinell hardness number. This figure shows the nature of the two line graphs that are not similar initially but gets closer in the ending. The experimental Brinell hardness number values for the experiment no. 5, 6, 7 and 9 almost match with predicted value.

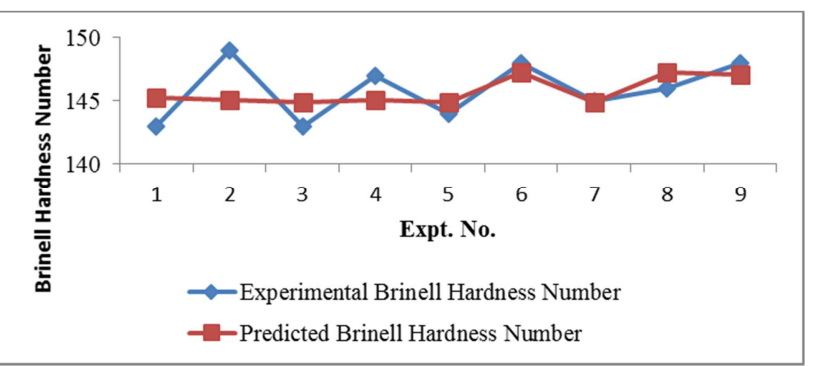

Figure 6. Comparison of Predicted and Experimental Brinell Hardness Number.

\subsubsection{Ultimate Tensile Strength}

The regression equation of ultimate tensile strength for the investment casting is as follows:

Ultimate Tensile Strength $(\mathrm{MPa})=474-0.060$ Pouring
Temperature $\left({ }^{\circ} \mathrm{C}\right)+0.7$ Preheat Time $(\mathrm{hrs})+0.067$ Preheat Temperature $\left({ }^{\circ} \mathrm{C}\right)$

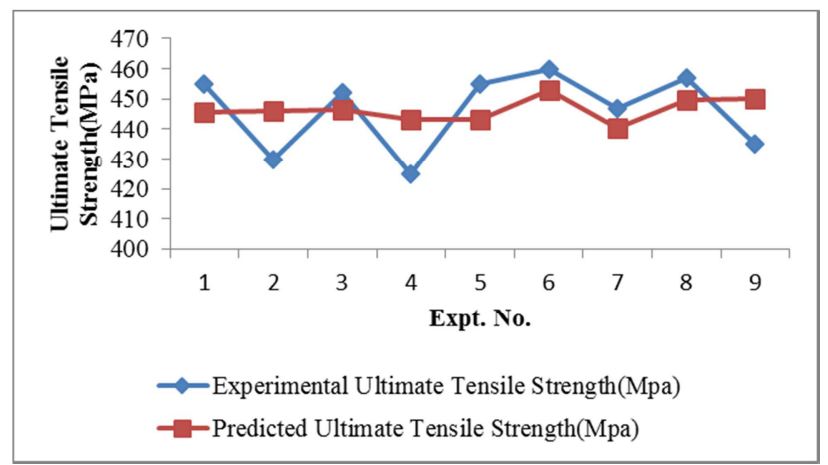

Figure 7. Comparison of Predicted and Experimental Ultimate Tensile Strength.

Figure 7 shows the comparison between experimental and predicted ultimate tensile strength. This figure shows the nature of the two line graphs that looks like parallel in the most portion of the full segment except 2 or 3 points. The experimental ultimate tensile strength values for the experiment no. 1, 3, 6, 7 and 8 almost match with predicted value.

\section{Conclusion}

Fabrication and mechanical tests of investment casting were performed carefully. The combination of preheat time: $2 \mathrm{hrs}$, preheat temperature: $950^{\circ} \mathrm{C}$ and pouring temperature: $1550^{\circ} \mathrm{C}$ values were the optimum setting for obtaining maximum Brinell hardness number. On the other hand, the combination of preheat time: $2.5 \mathrm{hrs}$, preheat temperature: $1000^{\circ} \mathrm{C}$, and pouring temperature: $1500^{\circ} \mathrm{C}$ values were the optimum setting for obtaining maximum ultimate tensile strength. From Taguchi analysis, it is seen that pouring temperature is the most influential factor to improve Brinell hardness number and ultimate tensile strength. From the ANOVA table, maximum contribution on the Brinell hardness number (59.21\%) and ultimate tensile strength $(92.85 \%)$ were found for pouring temperature. The regression equation showed a very close relation between predicted and experimental values.

\section{References}

[1] R. Singh, Sunpreet S., M. s. J. Hashmi, "Investment Casting", Materials Science and Materials Engineering, Elsevier, pp. 118, (2016) DOI: 10.1016/B978-0-12-803581-8.04163-1.

[2] Saroj Rani Pattnaik, D. Benny Karunakar, PK Jha, "Development in investment casting process-A review," Journals of Material Processing Technology, Vol. 212, Issue 11, pp. 2332-2348 (2012).

[3] Sarojrani Pattnaik, "Influence of sawdust on the properties of the ceramic shell used in investment casting process" The International Journal of Advance Manufacturing Technology, Springer, Vol. 93, Issue 1-4, pp. 691-707 (2017), DOI $10.1007 / \mathrm{s} 00170-017-0559-8$. 
[4] Dingdong Wang "Dimensional shrinkage prediction based on displacement field in investment casting", The International Journal of Advance Manufacturing Technology, Springer, Volume 85, pp 201-208 (2016), DOI: 10.1007/s00170-015-7836-1.

[5] Sushil Kumar, "Optimization of green sand casting process parameters of a foundry by using Taguchi's method", The International Journal of Advance Manufacturing Technology, vol. 55, Issue 1-4, pp. 23-34 (2011), DOI 10.1007/s00170010-3029-0.

[6] S. Jones, M. R. Jolly and K. Lewis, "Development of techniques for predicting ceramic shell properties for investment casting", British Ceramic Transaction, Vol. 101, Issue 3, pp. 106-113 (2002).

[7] S. Jones, C. Yuan, "Advances in shell molding for investment casting", Journal of Materials Processing Technology, Vol. 135 , pp. $258-265$ (2003).

[8] C. Yuan, S. Jones, "Investigation of fiber modified ceramic moulds for investment casting" Journal of the European Ceramic Society, Vol. 23, pp. 399-407 (2003).
[9] Gundi Baumeister, Brando Okolo, Joachim Rogner, "Micro casting of Al bronze: Influence of casting parameters on the microstructures and the mechanical properties". Microsystems Technology, Vol. 14, pp. 1647-1655 (2008).

[10] Pradeep Kumar, Sudhir Kumar, H. S. Shan, "Characterization of the refractory coating material used in vacuum assisted evaporative pattern casting", Journal of Material Processing Technology, Vol. 209, pp. 2699-2706 (2009).

[11] Taguchi G, Hocheng H; "Taguchi methods, orthogonal arrays and linear graphs, tools for quality engineering, Dearborn, MI: American Supplier Institute, pp. 35-38, (1987).

[12] M. Viquar Mohiuddin, "Influence of process parameters on quality of Al7SiMg alloy casting using statistical techniques", Materials Today: Proceedings 3, Elsevier pp. 3726-3733, (2016).

[13] Ross PJ; Taguchi technique for quality engineering. McGrawHill International Editions, Singapore. 1996.

[14] Roy RK; A primer on Taguchi method. New York: Van Nostrad Reinhold, 1990. 